\title{
Simultaneous Determination of Catechol and Hydroquinone using N, P co-doped Carbon Derived from Ionic Liquid
}

\author{
Yan $\mathrm{Ma}^{1,2}$, Zhanping Cao ${ }^{1,2, *}$, Ye Wang ${ }^{1,2}$, Yingli Xia ${ }^{1,2}$, Chongchong $\mathrm{He}^{1,2}$, Leilei Wang ${ }^{1,2}$, Saisai \\ Bao $^{1,2}$, Pingmei Yin ${ }^{1,2}$, Lili Wang ${ }^{1,2}$, Jian Gao ${ }^{1,2}$, Hong Wang ${ }^{1,3}$, \\ Zhen Yin ${ }^{1,2, *}$ \\ ${ }^{1}$ State Key Laboratory of Separation Membranes and Membrane Process, Tianjin Polytechnic \\ University, Tianjin 300387, China \\ ${ }^{2}$ School of Environmental and Chemical Engineering, Tianjin Polytechnic University, Tianjin 300387, \\ China \\ ${ }^{3}$ School of Material Science and Engineering, Tianjin Polytechnic University, Tianjin 300387, China \\ *E-mail: caozhanping2012@126.com; yinzhen@tjpu.edu.cn
}

doi: $10.20964 / 2019.04 .64$

Received: 19 November 2018 / Accepted: 27 February 2019 / Published: 10 March 2019

The N, P co-doped carbon (N-P-C) was prepared with the ionic liquid (IL) of hydrated pyridium dihydrate phosphate ([Hpdy]DHP). As precursors via one-pot pyrolysis. The N-P-C was used to modify the glassy carbon electrode (GCE) for simultaneous determination of hydroquinone (HQ) and catechol (CC). The obtained N-P-C was characterized by scanning electron microscopy (SEM), transmission electron microscopy (TEM), X-ray photoelectron spectroscopy (XPS), Raman spectroscopy and electrochemical techniques. Cyclic voltammetry (CV) and differential pulse voltammetry (DPV) techniques were employed to investigate the catalytic performance of simultaneous determination of HQ and CC. The N-P-C/GCE exhibits wide linear responses (from 5 to $400 \mu \mathrm{M}$ ), low detection limit $(0.98$ $\mu \mathrm{M}$ for $\mathrm{HQ}$ and $0.61 \mu \mathrm{M}$ for $\mathrm{CC}$, ratio of signal-to-noise 3 ) and superior sensitivity of $1.1 \mathrm{AM}^{-1} \mathrm{~cm}^{-2}$ for $\mathrm{HQ}$ and $1.4 \mathrm{AM}^{-1} \mathrm{~cm}^{-2}$ for $\mathrm{CC}$ in the simultaneous detection of $\mathrm{HQ}$ and $\mathrm{CC}$, demonstrating superior detection performance even compared with the state-of-art carbon materials, such as N-doped graphene, graphene oxide or carbon nanotubes. Moreover, it displayed the favorable reproducibility and good longterm stability.

Keywords: Ionic liquids, N, P co-doped carbon, Hydroquinone, Catechol, Simultaneous determination

\section{$\underline{\text { FULL TEXT }}$}

(C) 2019 The Authors. Published by ESG (www.electrochemsci.org). This article is an open access article distributed under the terms and conditions of the Creative Commons Attribution license (http://creativecommons.org/licenses/by/4.0/). 